\title{
Pozzolanic Activity of Nano-Silica and Its Application for Improving Physical, Mechanical and Structural Properties of Hardened Cement
}

\author{
A. E. Al-Salami and M. A. Al-Gawati
}

\begin{abstract}
The aim of this work is to investigate the pozzolanic activity of nano-silica (NS) prepared by sol-gel method and to study its application for improving physical, mechanical and structural properties of hardened blended cement. The NS was mixed with calcium hydroxide $(\mathrm{CH})$ by different ratios $10 \%, 20 \%, 30 \%$ and $50 \%$ using water to $\mathrm{CH}$ ratio of 0.35 , the mixtures were kept at relative humidity $100 \%$ for 7 days. After curing for 7 days, the reactions mechanisms were investigated by differential scanning calorimeter (DSC), $\mathrm{X}$-ray diffraction (XRD) and scanning electron microscope (SEM).

It was found that, NS consume the $\mathrm{CH}$ and produce calcium silicate hydrate (CSH) (strength responsible phase in cement). The ratio of $\mathrm{CH}$ consumed increases with increasing NS ratio. The studied NS was characterized by great reactivity i.e. it is a good pozzolanic material that can be used for improving cement and concrete properties. Blended cement paste samples were prepared by partial replacement of cement by different ratios of NS $0.5 \%, 1 \%, 1.5 \%, 2 \%$ and $2.5 \%$. The compressive strength, capillary water absorption and microstructure of NS-blended characteristics were studied at 28 days of curing. An enhancement in compressive strength by about $21 \%$ was obtained at $2 \%$ of NS. Capillary water absorption was reduced with increasing NS ratio. The reduction rate was $18.29 \%$ at $2 \%$ of NS. The microstructure of NS-blended cement appeared quite dense and compact with less micro pores.
\end{abstract}

Index Terms-Pozzolanic activity, cement, nano-silica, DSC, XRD, SEM, TEM.

\section{INTRODUCTION}

Pozzolanas are described as siliceous and aluminous materials, which react with lime to produce cementitious compounds [1]. The mineralogical composition, particle size distribution, and degree of amorphousness are the main factors affecting the pozzolanic activity of pozzolaninc clay [2]. Nano-Silica(NS) possess pozzolanic nature since it chemically reacts with calcium hydroxide $\mathrm{Ca}(\mathrm{OH})_{2}(\mathrm{CH})$ released during cement hydration and convert it to calcium silicate hydrate $(\mathrm{CSH})$ which is the strength responsible phase, therefore it has been used to increase strength, durability and sulphate resistance of cement pastes [3]. NS particles uniformly distribute through cement matrix and act as nucleation centers for hydration products this in turn will accelerate the cement hydration rate. Due to its ultrafine size, NS causes packing i.e. act as filler into interstitial spaces

Manuscript received August 8, 2013; revised December 20, 2013.

The authors are with Physics Dept., Faculty of Science, king Khalid University, Abha, Saudi Arabia (e-mail: mahmoudgawati@gmail.com). inside the skeleton of hardened microstructure of cement paste and thus increasing the mechanical compressive strength. The small particles of pozzolanic silica fill the remaining voids in the young and partially hydrated cement paste, increasing its final density [4], [5]. NS can improve the microstructure and reduce the water permeability of hardened concrete [6]. The NS particles fill the voids of the CSH-gel structure and act as nucleus to tightly bond with CSH-gel particles, this means that NS application reduces the calcium leaching rate of cement pastes and therefore increasing their durability [7], [8]. Finally the NS addition to cement increases density, strength, durability and reduces porosity of hardened blended cement and concrete [3], [6] -[8]. The aim of this work is to investigate the pozzolanic activity of nano-silica (NS) prepared by sol-gel method and to study its application for improving physical, mechanical and structural properties of hardened blended cement.

\section{EXPERIMENTAL PROGRAM}

\section{A. Materials}

- Nano-silica (NS): the NS used in this study was prepared by the authors using sol-gel method; it is amorphous as shown from XRD pattern in Fig. 1. SEM and TEM, EDAX chart indicate that NS is characterized by spherical morphology and high purity, also the particle size is less than $13 \mathrm{~nm}$ as shown in Fig. 2 and Fig. 3. The specific surface area of NS is about $459 \mathrm{~m}^{2} / \mathrm{g}$.

- Calcium hydroxide (CH): purity $96 \%$.

- Ordinary Portland cement (OPC): the cement used in this study was supplied by southern cement Co.

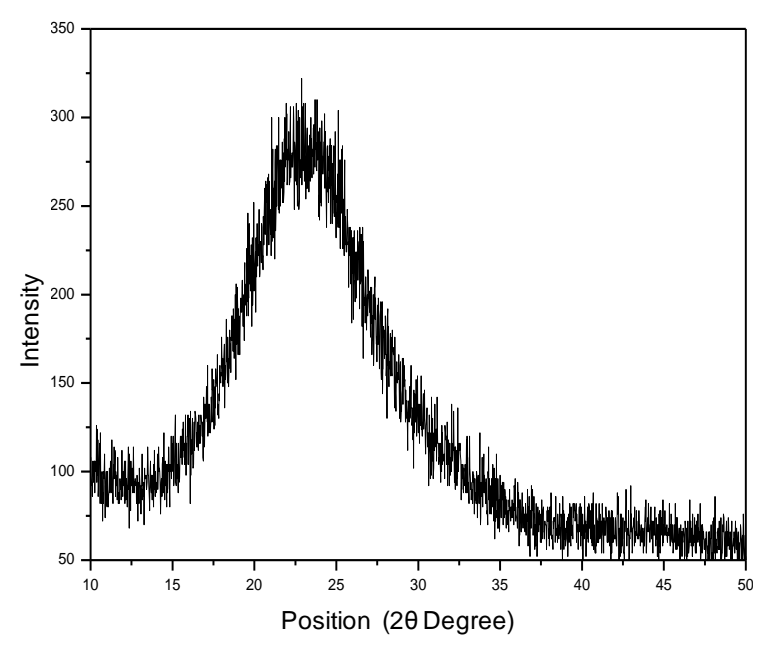

Fig. 1. XRD pattern of NS. 


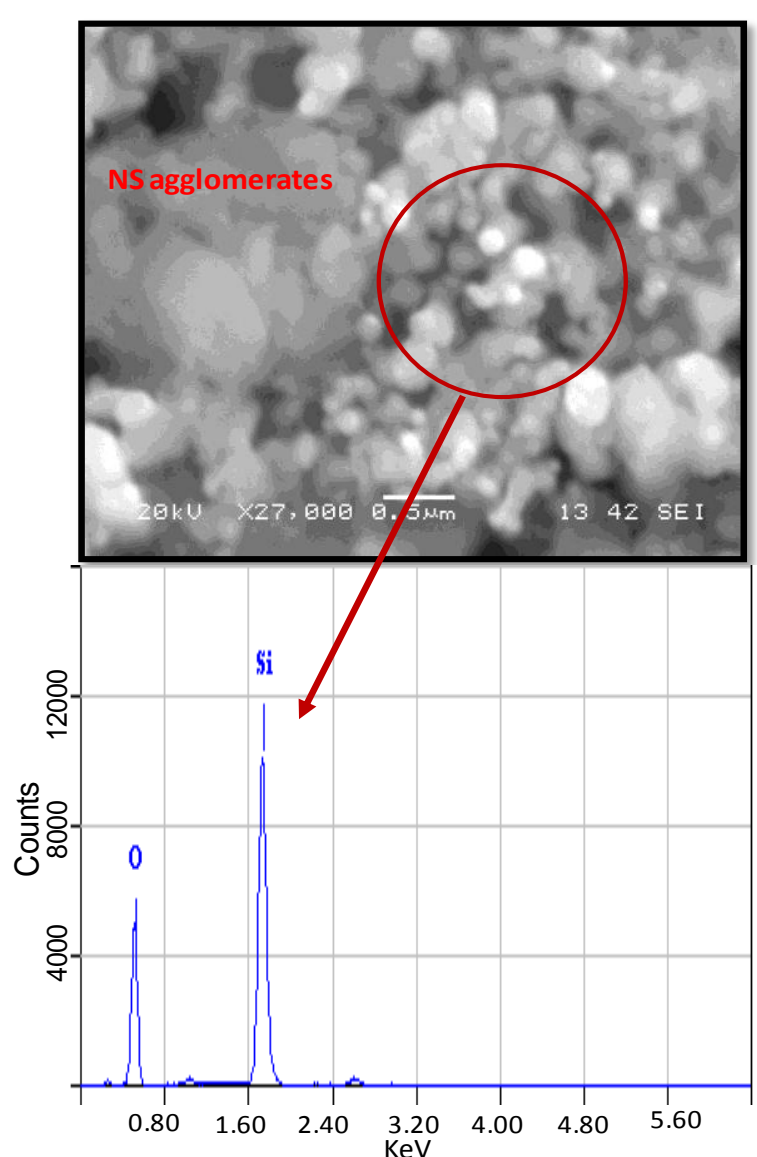

Fig. 2. SEM and EDAX graphs for NS.

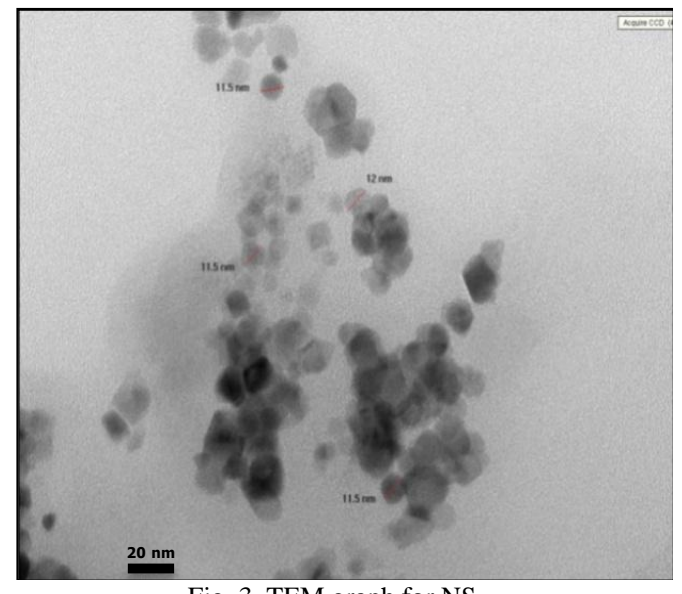

Fig. 3. TEM graph for NS.

\section{B. Samples Preparation and Testing}

\section{1) Pozzolanic activity of the prepared nano-silica}

The pozzolanic activity of the prepared Nano-silica (NS) was studied through the investigation of reaction mechanism with calcium hydroxide $(\mathrm{CH})$. NS was mixed with $\mathrm{CH}$ with different ratios $10 \%, 20 \%, 30 \%$ and $50 \%$ using water to calcium hydroxide ratio $=0.35$ the mixtures were kept at relative humidity $100 \%$ for 7 days. After curing for 7 days, the mixtures were tested by DSC, XRD and SEM.

\section{2) Development of NS-blended cement samples}

To study the effect of NS on the hardened cement, blended cement paste samples were prepared with partial replacement of cement by different ratios of NS $0.5 \%, 1 \%, 1.5 \%, 2 \%$ and $2.5 \%$. The cement pastes were prepared using the standard water of consistency. The NS particles were first dispersed in the water of hydration using ultrasonic bath for 10 minutes to assure good dispersion of NS and avoid agglomeration. In this case the mixture is now ready for addition into the cement to make pastes. The cement pastes samples were prepared as cubes $5 \times 5 \times 5 \mathrm{~cm}$ The samples were kept in molds for $24 \mathrm{~h}$, and then cured in water for 28 days for capillary water absorption and compressive strength tests. Fig. 4 shows the experimental set up of capillary water absorption test, in this test the specimens were dried in oven at about $105^{\circ} \mathrm{C}$ until constant mass was obtained. The sides of the specimen were coated with paraffin to achieve unidirectional flow. The specimens were exposed to water on one face by placing it on slightly raised seat (about $5 \mathrm{~mm}$ ) on a pan filled with water. The water on the pan was maintained about $5 \mathrm{~mm}$ above the base of the specimen during the test. The weight of the specimen was measured at regular $30 \mathrm{~min}$ interval up to $2.5 \mathrm{~h}$ to get the little absorption variation of water. The capillary absorption coefficient $(k)$ was calculated by using formula $k=W /(A \sqrt{t})$ where $W$ is the amount of water a absorbed in gram, $A$ is the cross sectional area in $\left(\mathrm{cm}^{2}\right)$ contact with water and $t$ is the time in second [9].

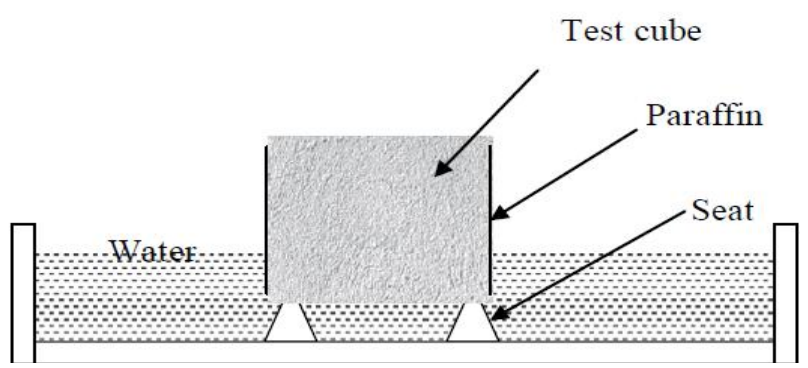

Fig. 4. Experimental setup of capillary water absorption test.

\section{RESUlTS AND DISCUSSION}

A. Pozzolanic Activity

1) Differential scanning calorimeter (DSC)

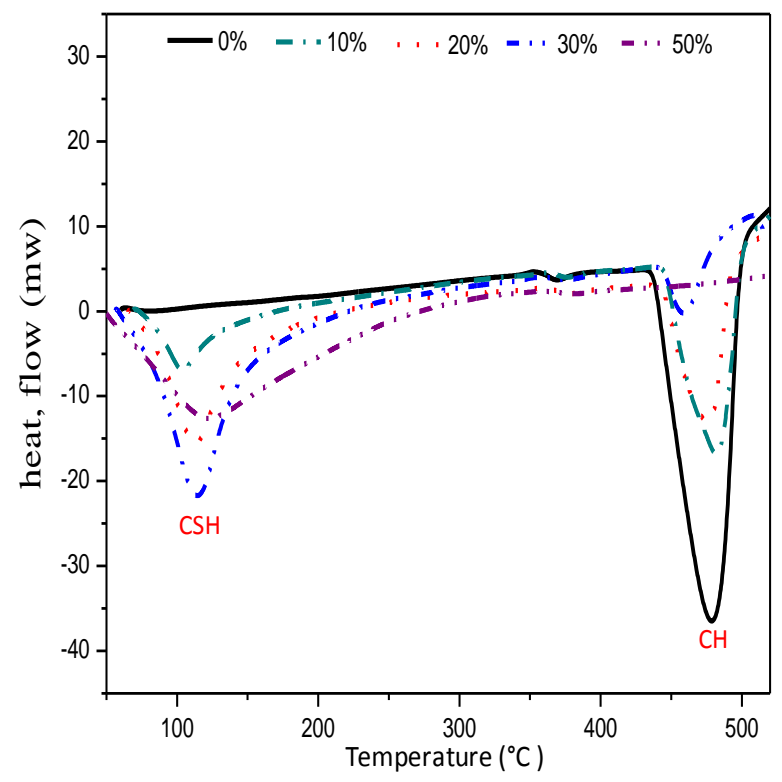

Fig. 5. DSC thermographs of $\mathrm{CH}$ with different ratios of NS.

Fig. 5 shows the DSC thermographs of the testing samples the brooding peak from $105^{\circ} \mathrm{C}$ to $180^{\circ} \mathrm{C}$ represents the $\mathrm{CSH}$ 
phase and the peak from $450^{\circ} \mathrm{C}$ to $475^{\circ} \mathrm{C}$ represents the $\mathrm{CH}$ phase, $\mathrm{CSH}$ peak increases at expense of $\mathrm{CH}$ peak, that is meaning; the Nanao-silica(NS) reacts with calcium hydroxide $(\mathrm{CH})$ to produce calcium silicate hydrate $(\mathrm{CSH})$ which is the main phase responsible of the strength in hardened cement. Fig. 6 shows the curve of heat formation for the $\mathrm{CSH}$ and $\mathrm{CH}$ against NS ratio it is clear as the amount of NS increases the value of heat formation energy of $\mathrm{CH}$ phase decreases while heat formation of CSH is increasing, which led to the enhancement of the physical and chemical properties of blended cement due the addition of the pozzolanic NS.

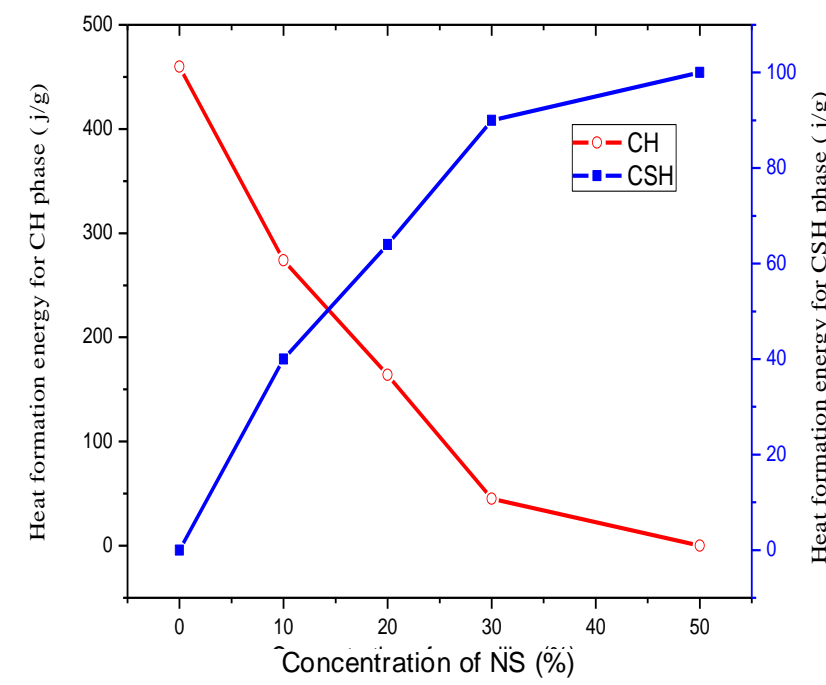

Fig. 6.Variation of the heat formation for $\mathrm{CSH}$ and $\mathrm{CH}$ phases with different ratios of NS.

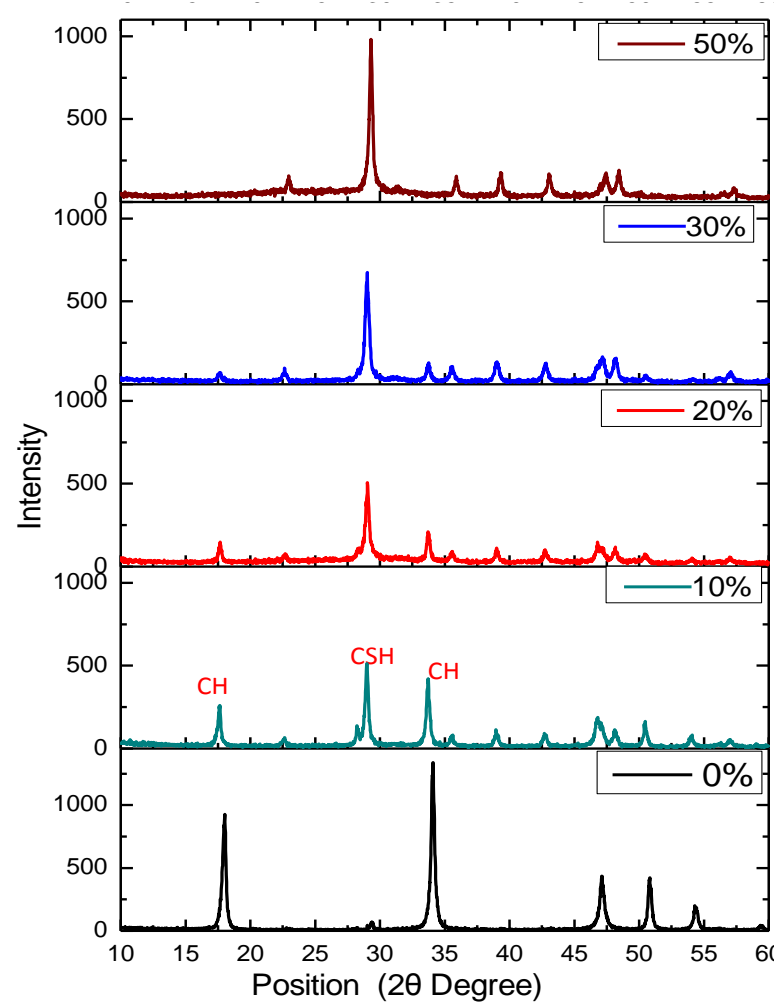

Fig. 7. XRD patterns of $\mathrm{CH}$ with different ratios of NS.

\section{2) X-ray diffraction spectroscopy $(X R D)$}

Fig. 7 shows the XRD patterns for pure $\mathrm{CH}$ and $\mathrm{CH}$ with NS at different ratios. peaks at $2 \theta=18^{\circ}$ and $2 \theta=33^{\circ}$ are related to $\mathrm{CH}$ phase and the peak at $2 \theta=29^{\circ}$ is related to $\mathrm{CSH}$ phase as clear the peak for $\mathrm{CSH}$ is increasing and the $\mathrm{CH}$ peaks is decreasing with increasing the amount of NS, at $50 \%$ NS the peaks of $\mathrm{CH}$ were disappeared that agree with thermal analysis results which indicate that $\mathrm{CH}$ phase is totally consumed at this ratio.

\section{3) Microstructure characteristics}

Fig. 8 shows the SEM micrographs of the pure $\mathrm{CH}$ and a mixture of $\mathrm{CH}$ with $30 \% \mathrm{NS}$. As clear from Fig. 8 A) the calcium hydroxide has flake like structure, but in Fig. 8 B) adding the NS to $\mathrm{CH}$ led to formation of the $\mathrm{CSH}$ gel like structure with the existence of some crystalized $\mathrm{CH}$.
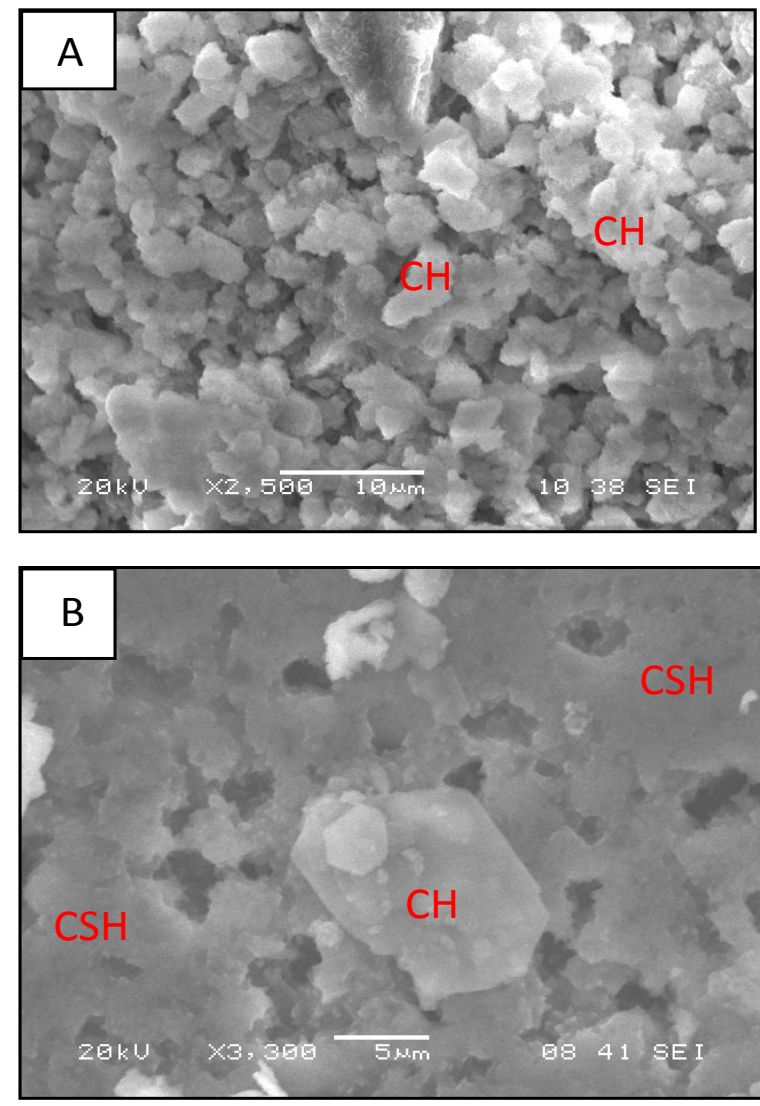

Fig. 8. SEM micrographs for A) pure $\mathrm{CH}$, B) $\mathrm{CH}$ With $30 \%$ NS hydrated.

\section{B. Effect of NS on Properties of Blended Cement}

\section{1) Compressive strength NS-blended cement}

The compressive strength of the NS-blended cement with NS ratio at 28 days of curing is shown in Fig. 9. It is clear that the compressive strength increases with increasing NS ratio up to $2 \%$. An enhancement of about $21 \%$ relative to plain pastes was observed at $2 \%$ NS. The increase of compressive strength is due to the high pozzolanic activity of NS in which it chemically reacts with $\mathrm{CH}$ released during cement hydration and results in the formation of additional CSH which is the strength responsible phase. Due to its ultrafine size, NS causes packing i.e. act as filler into interstitial spaces inside the skeleton of hardened microstructure of cement paste and thus increasing the mechanical compressive strength. As NS particles uniformly distribute in the cement matrix they act as nucleation centres for hydration products this in turn will accelerate the cement hydration rate. The degradation of strength above $2 \%$ NS may be due to 
agglomeration of NS particles with defects generated in dispersion of NS particles that causes weak zones inside skeleton [10], [11].

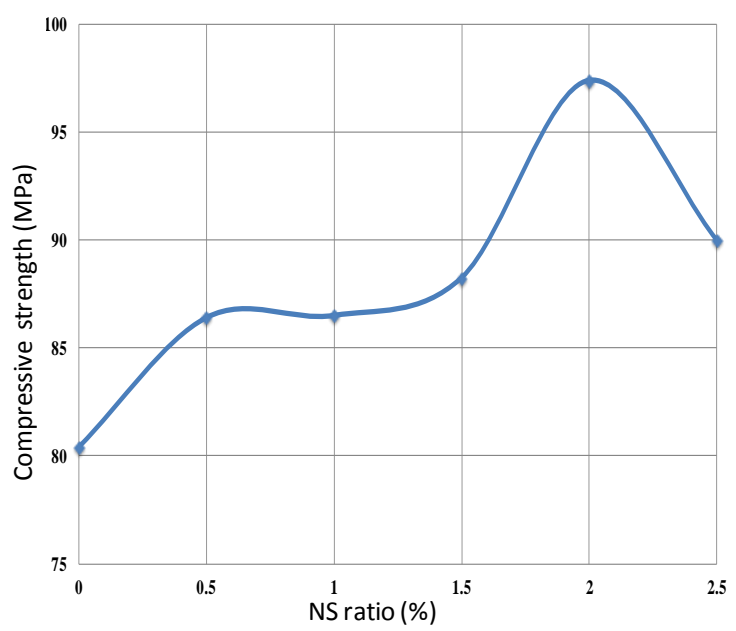

Fig. 9. Compressive strength of NS-blended cement.

\section{2) Effect of NS on capillary water absorption of} NS-blended cement

The effect of NS on the capillary water absorption of cement is shown in Fig. 10. It can be seen that the water absorption coefficient decreases with increasing NS ratio, this is due to the improvement of microstructure. Due to its ultra fine size, NS fill the voids and micro pores inside the cement matrix this resulted in a reduction of capillary absorption. In addition the pozzolanic reaction of NS with free $\mathrm{CH}$ resulted in the creation of more $\mathrm{CSH}$ which fill the internal capillary pores and make the structure uniform, compact and dense as will be seen from SEM Fig. 11. Densification of cement matrix results in the immobilization of water inside the bulk paste [12]. The durability of cement and concrete structures is closely related to the water absorption coefficient so the reduction of water absorption will extend life time of cement based products and enhance durability [13]. From this point of view it can be concluded that NS, is beneficial for enhancing durability of NS-blended cement or concrete.

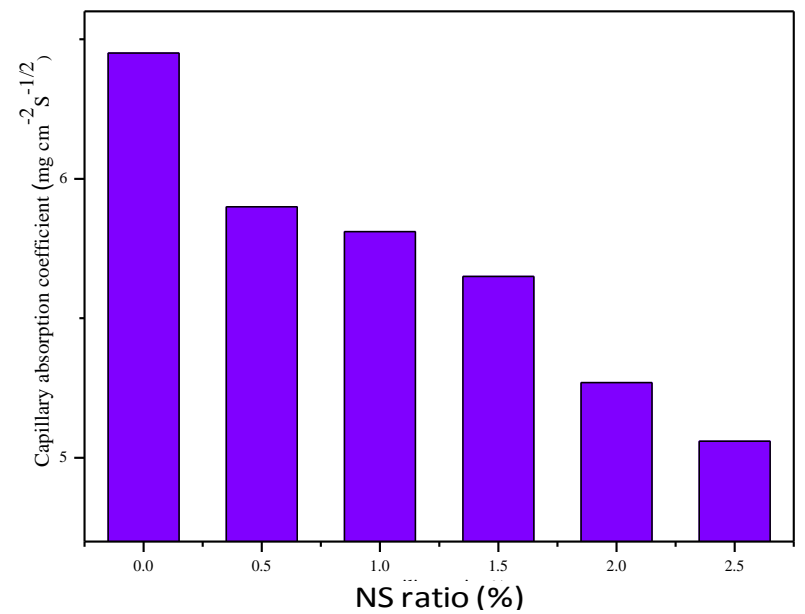

Fig. 10. Capillary water absorption of NS-blended cement.

3) Microstructure characteristics of NS-blended cement

Fig. 11 Shows the SEM micrographs of both plain and
NS-blended cement pastes at 28 days of hydration. As shown in Fig. 11 a) The phases identified for plain cement paste are the nearly amorphous $\mathrm{CSH}$, needle and plate shaped particles stacked in layers of $\mathrm{CH}$ and hexagonal plates of monosulphate hydrate crystals. The replacement of Portland cement by Nanao-silica particles was found to influence the hydration behavior and led to differences in the microstructure of the hardened pastes. The microstructure of the hardened cement paste containing Nanao-silica appeared quite dense and compact with relatively less capillary pores as compared to the plain cement paste; furthermore, large crystals of $\mathrm{CH}$ are disappeared. The densification of cement paste is attributed to the pozzolanic reaction of NS which reduced the presence of $\mathrm{CH}$ crystals and increased the gel like $\mathrm{CSH}$ with strong hydraulic character.
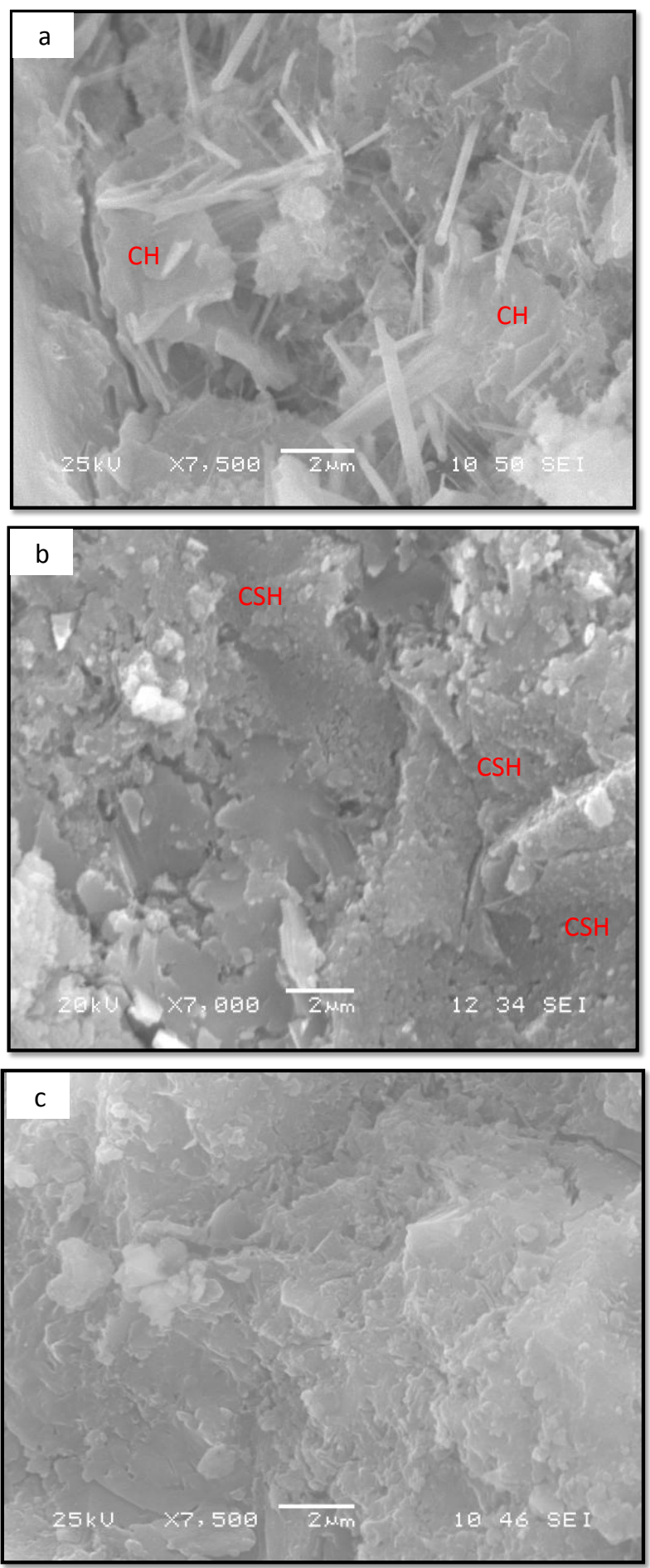


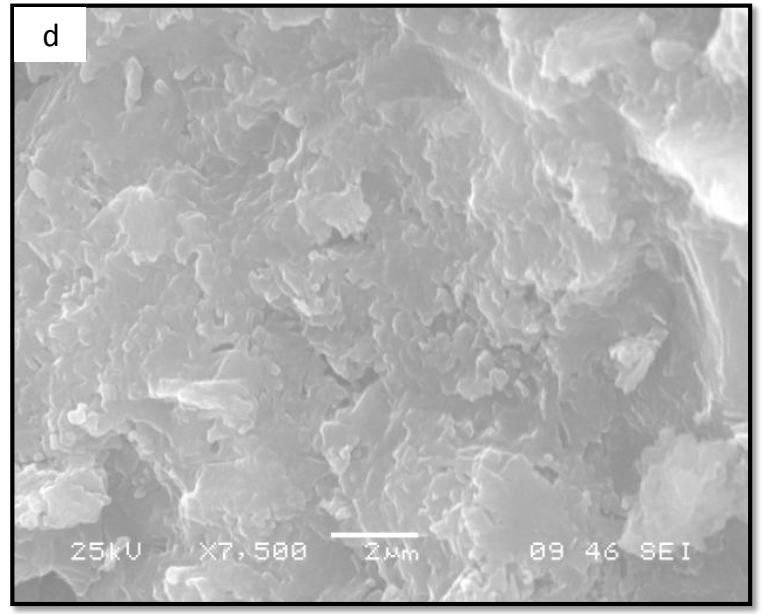

Fig. 11. SEM micrographs of NS-blended cement with different NS replacements a) $0 \%$ b) $1 \%$ c) $2 \%$ d) $2.5 \%$.

\section{CONCLUSION}

Nano-silica that was investigated in this study showed great pozzollanic activity in which it consumes large quantity of calcium hydroxide and convert it totally to calcium silicate hydrate even within 7 days of reaction, it is a good pozzolanic material that can be used for improving cement and concrete properties even at very small percentages. Nanosilica improved the properties of hydrated cement, $2 \%$ replacement of NS led to an enhancement in compressive strength of hardened cement by about $21 \%$ when compared with plain cement. The capillary water absorption reduction was $18.29 \%$ at $2 \%$ NS. The microstructure of NS- blended cement pastes appeared quite dense and compact with less voids or capillary pores.

\section{ACKNOWLEDGMENT}

This study was supported by King Abdulaziz City for Science and Technology (KACST), project code 10-ADV 1174-07. The authors are grateful for the financial support from KACST.

\section{REFERENCES}

[1] R. E. Davis, "A review of pozzolanic materials and their uses," in Proc. Symposium on the use of pozzolanic materials in mortars and concretes, ASTM Special Technical Publication, vol. 90, 1949, pp. $3-5$.
[2] F. Massazza, "Pozzolana and pozzolanic cements," in P. C. Hewlett, ed., Lea's chemistry of cement and concrete, UK: Elsevier, pp. 471-602, 1998.

[3] B. B. Sabir, S. Wild, and J. Bai, "Metakaolin and calcined clays as pozzolans for concrete: a review," Cement and Concrete Composites, pp. 441-454, 2001.

[4] A. Dunster, Silica fume in concrete, IHS BRE Press, Garston, Information paper $\mathrm{N}^{\circ}$ IP 5/09, U.K, 2009.

[5] S. Sakka and H. Kosuko, Handbook of sol-gel science and technology, vol. I, New York, USA: Solgel Processing, Kluwer Academic Publisher, 2000, pp. 9-10.

[6] T. Ji, "Preliminary study on the wate permeability and microstructure of concrete incorporating nano-SiO2," Cement and Concrete Research, vol. 35, pp. 1943-1947, 2005.

[7] Y. Qing, Z. Zenan, K. Deyu, and Ch. Rongshen, "Influence of nano-SiO2 addition on properties of hardened cement paste as compared with silica fume," Construction and Building Materials, vol. 21, pp. 539-545, 2007

[8] J. J. Gaitero, I. Campillo, and A. Guerrero, "Reduction of the calcium leaching rate of cement paste by addition of silica nanoparticles," Cement and Concrete Research, vol. 38, pp. 1112-1118, 2008.

[9] B. Nusret and Y. Salih, "Strength and capillary water absorption of lightweight concrete under different curing condition," Indian J Eng Mater Sci., vol. 17, pp. 145-51, 2010.

[10] M. S. Morsy, S. H. Alsayed, and M. Agel, "Effect of nano-clay on mechanical properties and microstructure of ordinary Portland cement mortar," Int. J Civil Environ Eng., vol. 10, pp. 23-27, 2010.

[11] H. Shoukry, M. F. Kotkata et al., "Flexural Strength and Physical Properties of Fiber reinforced Nano Metakaolin Cementitious Surface Compound," J Construct Build Mater, vol. 43 , pp. 453-460, 2013.

[12] J. Bijen, Benefits of slag and fly ash. Constr. Build Mater, vol. 10, pp. 309-314, 1996.

[13] M. Emerson, Mechnisms of water absorption by concrete, UK: Transport and Road Research Laboratory, 1990。

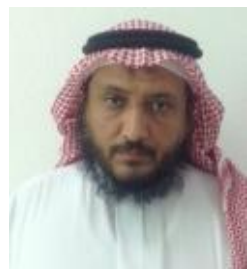

Ali E. Al-Salami is an associate professor of Solid State Physics, physics Dept., College of Science, King Khalid University, Abha, Kingdom of Saudi Arabia. Dr. Al-salami has Ph.D. in solid state physics (Blended Cement) from Cairo University. Egypt, 2006.

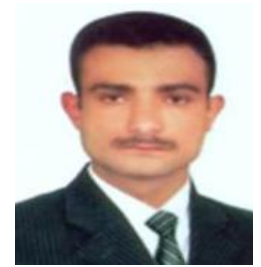

Mahmoud Ali Saleh Al-Gawati is a M.Sc. student in Physics Dept., College of Science King Khalid University, Abha, Kingdom of Saudi Arabia. He has B.Sc.Ed dgree in physics from Department of Physics Faculty of education Thamar University, Dhamar Yemen, 2006. 